\title{
Multiphysics modeling: electro-vibro-acoustics and heat transfer of induction machines
}

\author{
J. Le Besnerais ${ }^{1,4}$, A. Fasquelle ${ }^{1,2}$, M. Hecquet ${ }^{1}$, J. Pellé ${ }^{2}$, V. Lanfranchi ${ }^{3}$, S. Harmand ${ }^{2}$, P. Brochet ${ }^{1}$, and A. \\ Randria $^{4}$ \\ ${ }^{1}$ Laboratoire l'Electrotechnique de l'Electronique de Puissance de Lille (L2EP), Ecole Centrale de Lille, \\ Villeneuve d'Ascq, FRANCE \\ ${ }^{2}$ Laboratoire de Mécanique et d'Energétique de Valenciennes (LME), Valenciennes, FRANCE \\ ${ }^{3}$ Laboratoire de d'Electromécanique de Compiégne (LEC), Compiégne, FRANCE \\ ${ }^{4}$ ALSTOM Transport, \\ jean.le_besnerais@centraliens.net, aurelie.fasquelle@ec-lille.fr, vincent.lanfranchi@utc.fr, \\ michel.hecquet@ec-lille.fr
}

\begin{abstract}
The design of electrical machines involves several fields of physics, such as electromagnetism, thermics, mechanics but also acoustics. This paper describes the analytical multiphysics models of a computer-aided design (CAD) software which is applied to inverter-fed traction induction machines. The electromagnetic model computes rotor and stator currents, the induction machine traction characteristics, and the radial airgap flux density. The mechanical and acoustic model computes the motor audible magnetic noise level due to Maxwell forces. The thermal model based on 3D nodal network, computes the transient temperature of different parts of the motor. These fast models make it possible to couple the software with some optimization tools. Finally, some simulations are presented on a self-ventilated closed motor, and an example of multi-objective optimization is exposed.
\end{abstract}

Index Terms-Induction machine, magnetic noise, vibrations, multi-objective optimization, genetic algorithms.

\section{INTRODUCTION}

$\mathbf{M}$ ANY factors have to be taken into account at the design stage of a traction machine. Of course, electrical traction characteristics (output torque, efficiency) are very important, but the designer is also aware of thermal problems, especially for closed motor and in subway applications where the motor is subjected to a high number of short traction/braking cycles during the whole day. In such applications, the audible magnetic noise radiated by the machine has also to be limited in order to ensure passengers and residents comfort. Finally, the vibration levels also need to be predicted at the design stage.

The designer has therefore to predict the machine behavior in terms of electromagnetism, thermics, mechanics and acoustics. If some well-known finite element analysis (FEA) tools can compute these different motor characteristics, their coupling can be tedious and their computational time is usually prohibitive, particularly in an optimization process. In order to solve this problem, some analytical multiphysics models have been established and validated with numerical simulations or tests. This fast model, called DIVA, can be associated with a multiobjective constrained optimization tool to reach the optimal design of an induction machine [1], [2].
This paper first presents the different analytical models that have been used, specifying their assumptions and the different validations that have been made. The organization of DIVA models is presented in Fig. 1. Then, some typical simulation results are presented on a squirrel-cage induction machine. Finally, the limitations of this model are discussed.

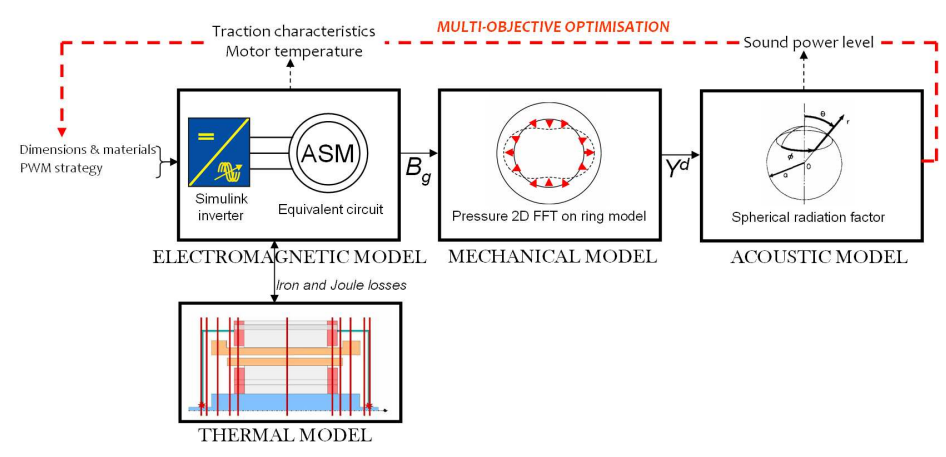

Fig. 1. DIVA models and their main input/output $\left(B_{g}\right.$ is the air-gap flux density distribution, $Y^{d}$ is the stator dynamic deflection).

\section{Electromagnetic MOdeL}

Stator current computation is based on a single phase equivalent circuit of the machine, where saturation effect is considered by computing a saturation factor [3], [4]. The harmonics generated by pulse-width modulation (PWM) are taken into account using an extended equivalent circuit [5], [6]. Stator currents have been validated with tests in sinusoidal case at several supply frequencies and saturation levels (Fig. 2) and with different PWM strategies (Fig. 3). Indeed, DIVA is coupled to a Simulink inverter model which can generate different PWM voltage patterns (asynchronous, synchronous, calculated angles, full wave, random PWM strategies).

Motor efficiency $\eta$ is computed as

$$
\eta=\frac{P_{o u t}}{P_{i n}}=\frac{P_{m e c}-P_{f r i c}-P_{i r}^{R}}{P_{e m}+P_{i r}^{S C}+P_{i r}^{S T}+P_{j}^{S}}
$$

where $P_{m e c}$ is the mechanical air-gap power, $P_{\text {fric }}$ is the friction power losses (experimentally determined), $P_{e m}$ is the 


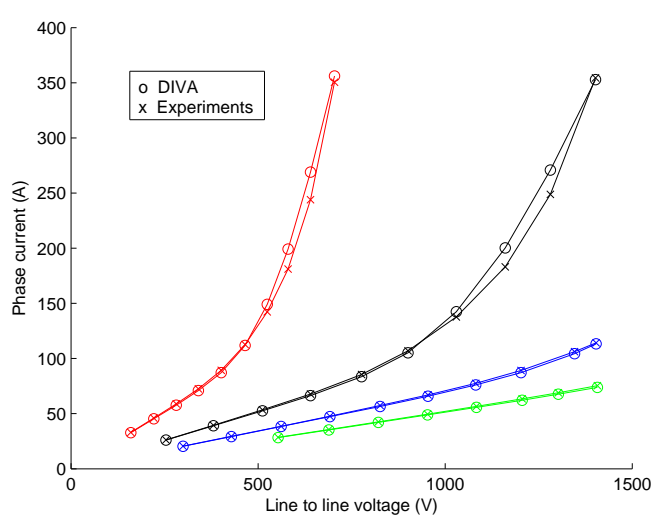

Fig. 2. Experimental and simulated stator phase currents in function of phase voltage at several supply frequencies $(50 \mathrm{~Hz}, 100 \mathrm{~Hz}, 150$ and $200 \mathrm{~Hz})$.

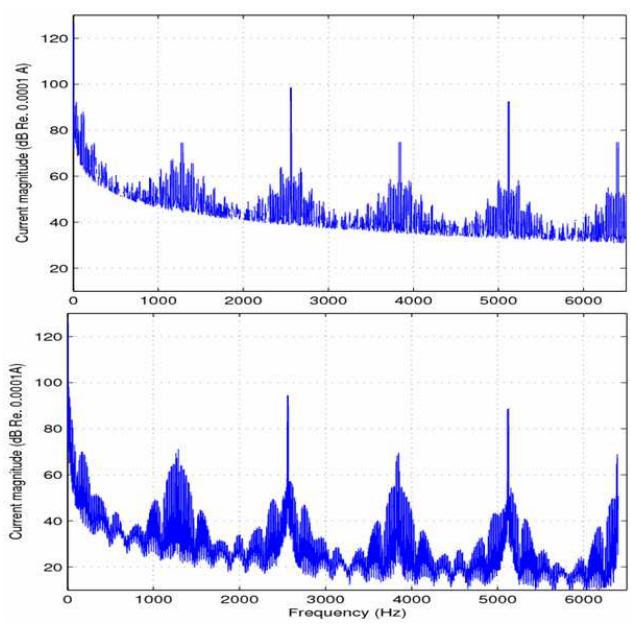

Fig. 3. Experimental (down) and simulated (up) stator phase current spectrum in asynchronous PWM mode (1280 Hz switching frequency, $150 \mathrm{rpm})$.

air-gap electromagnetic power, $P_{i r}^{R}$ represents rotor total iron losses which are concentrated in rotor tooth tips, $P_{i r}^{S Y}$ and $P_{i r}^{S T}$ stator yoke and teeth iron losses, and $P_{j}^{S}$ stator Joule power losses.

Iron losses are modeled with using a Bertotti-Steinmetz formula, where different coefficients are used for stator yoke, stator teeth and rotor regions [7], [8]:

$$
\begin{array}{r}
P_{s t}=2.110^{-2} f B_{s t}^{2}+1.610^{-4} f^{2} B_{s t}^{2}+2.510^{-3} f^{1.5} B_{s t}^{1.5} \\
P_{s y}=3.310^{-3} f B_{s y}^{3.47}+1.610^{-4} f^{2} B_{s y}^{2}+2.310^{-2} f^{0.88} B_{s y}^{1.38} \\
P_{r t}=9.810^{-5} Z_{r} f_{r} B_{r t}^{2}
\end{array}
$$

where $P_{s t}, P_{s y}$ and $P_{r t}$ respectively stands for stator teeth, stator yoke and rotor iron losses $(\mathrm{W} / \mathrm{kg}), B_{s t}, B_{s y}$ and $B_{r t}$ are the fundamental stator teeth, stator yoke and rotor teeth flux densities, $f$ is the fundamental stator supply frequency, $f_{r}$ is the rotor mechanical frequency, and $Z_{r}$ is the number of rotor teeth.

These coefficients were adapted to finite element simulations realized at different frequencies (see Fig. 4). Teeth and yoke flux densities are estimated using some classical flux conservation-based laws [3].

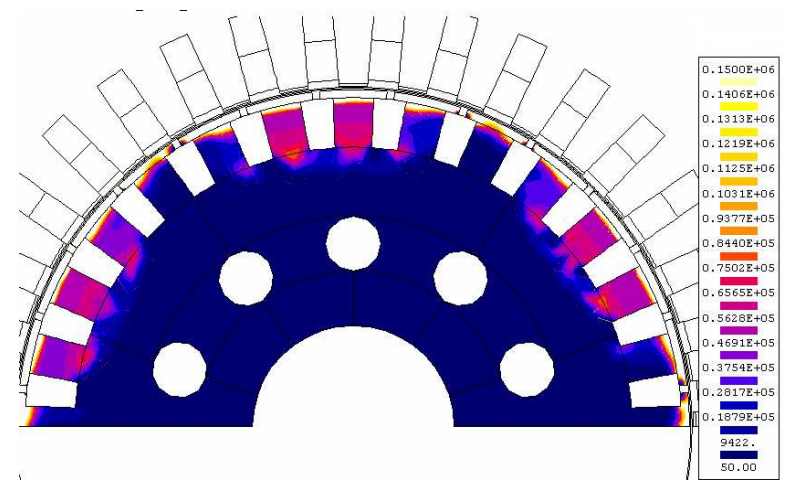

Fig. 4. Example of rotor iron losses distribution computed with FLUX2D Loss Surface module.

The air-gap radial flux-density distribution, which is used in order to compute the magnetic force distribution acting on stator core, is computed as the product of magnetomotive force and air-gap permeance, assuming that the air-gap flux density lines are almost radial (infinite magnetic permeability of the iron). The flux density shape has been validated with the FEA software FLUX2D [9] (Fig. 5 and 6).

Magnetic vibrations and acoustic noise of the motor are supposed to come from the stator stack excitation by radial Maxwell pressure $P_{M}$ [10], [11], [12]:

$$
P_{M}=\frac{B_{g}^{2}}{2 \mu_{0}}
$$

where $B_{g}$ is the air-gap radial flux density.

This magnetic pressure distribution is shown in Fig. 7.

\section{MECHANICAL AND ACOUSTIC MODELS}

The mechanical behavior of the stator stack is predicted using an 2D equivalent ring model, whose natural frequencies are also computed analytically [5], [6]. Natural frequencies

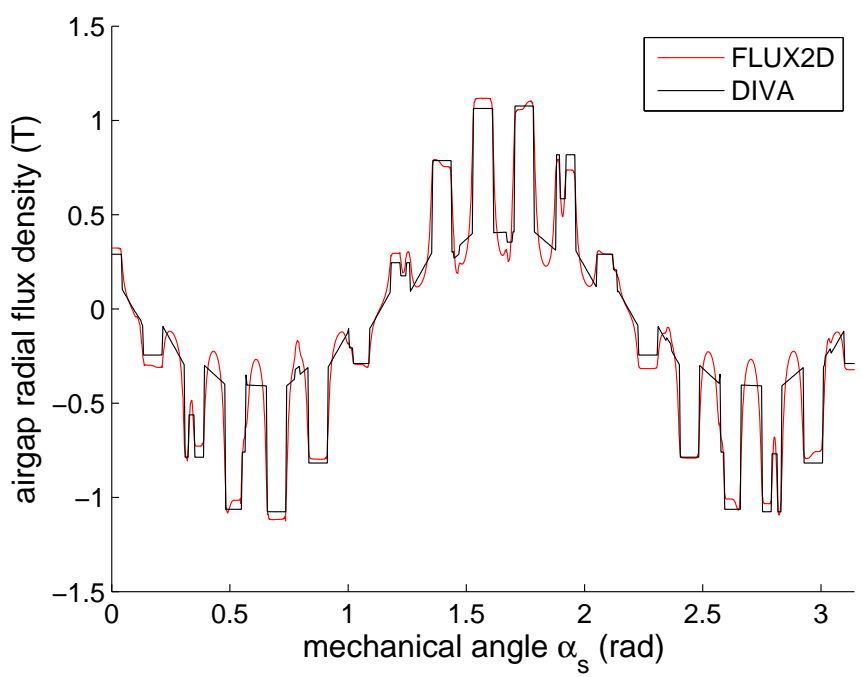

Fig. 5. FEA and DIVA radial flux density distribution along the air-gap at time $t=0$. 


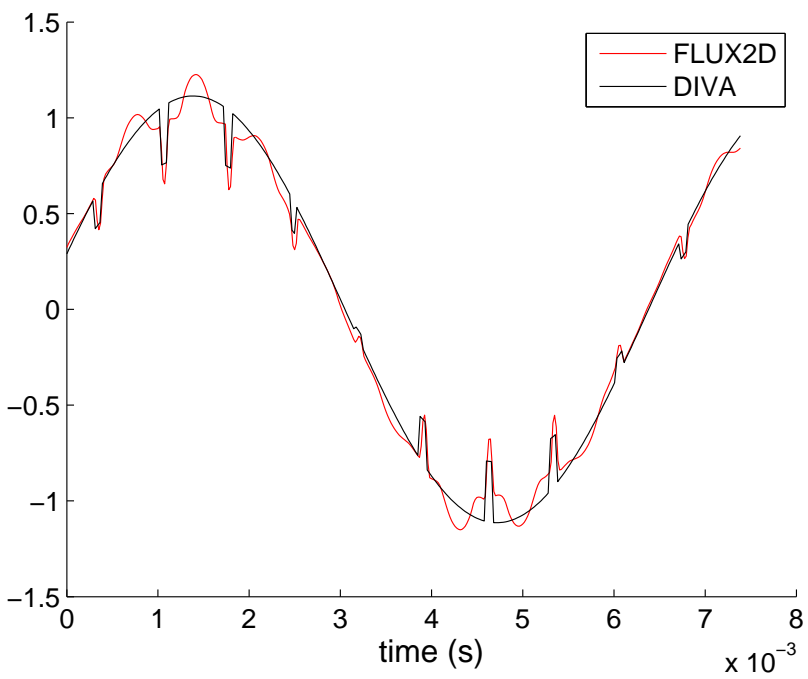

Fig. 6. FEA and DIVA radial flux density distribution in function of time at angle $\alpha_{s}=0$.

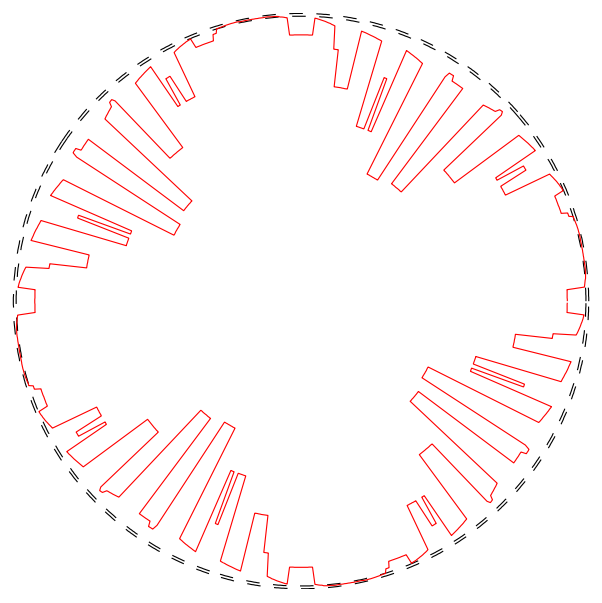

Fig. 7. Radial Maxwell pressure distribution along the air-gap at a given time.

computation were validated on a smaller motor by FEA and experiments (operational modal analysis [13], see Table I).

\section{TABLE I}

STATOR NATURAL FREQUENCIES COMPUTATION (HZ) USING DIFFERENT METHODS. OR: OUT OF RANGE, ND: NON DEFINITE.

\begin{tabular}{|c|c|c|c||c|c|}
\hline$m$ & 2-D FEM & Shock Method & Sinus Method & DIVA & OMA \\
\hline 0 & 14656 & OR & OR & 14859 & 14400 \\
1 & ND & 1200 & 1273 & 1234 & 1148 \\
2 & 2364 & 2400 & 2423 & 2485 & 2245 \\
3 & 6473 & 6100 & 6210 & 6415 & 6370 \\
4 & 11898 & 11700 & OR & 12065 & 11790 \\
\hline
\end{tabular}

The exciting force is developed in a 2D Fourier series (Fig. 8 ) of force waves with spatial order $m$ and frequency $f$. The static deflection of the stator can then be computed analytically for each sinusoidal wave [10]. Dynamic deflections are obtained using a second order filter with the computed natural frequencies and damping [11].
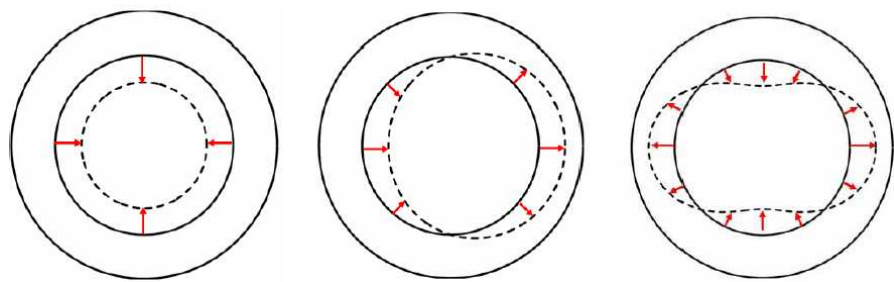

Fig. 8. Illustration of the electromagnetic force decomposition in several sinusoidal force waves (spatial orders 0,1 and 2). The magnitude, velocity, propagation direction of these elementary force waves are given by the $2 \mathrm{D}$ FFT of the air-gap electromagnetic pressure distribution.

The radiation efficiency of the stator is modeled using its analytical expression of a pulsating sphere or infinite cylinder according to its dimensions [14].

The vibration level was validated with tests [6], and the sound power level was validated coupling a FEA software (Ideas) with a boundary element software (Sysnoise) (see Fig. 9).

More details about this part of the model can be found in [6], [15].

\section{THERMAL MODEL}

A 3D nodal network-based thermal model is used in order to compute the motor temperature in transient state. This method consists in dividing the machine in small isothermal volumes whose center is represented by nodes. Each node of the 3D nodal network is then associated to a volume $V_{i}$, a temperature $T_{i}$, a heat capacity $C_{i}$, and a heat sink/source $P_{i}$. By analyzing the types of heat transfers (convective, diffusive, etc) occurring in the different parts of the machine, nodes can be connected one to another with equivalent thermal conductances $G_{i j}$.

The evolution of nodes temperature therefore follows the equation :

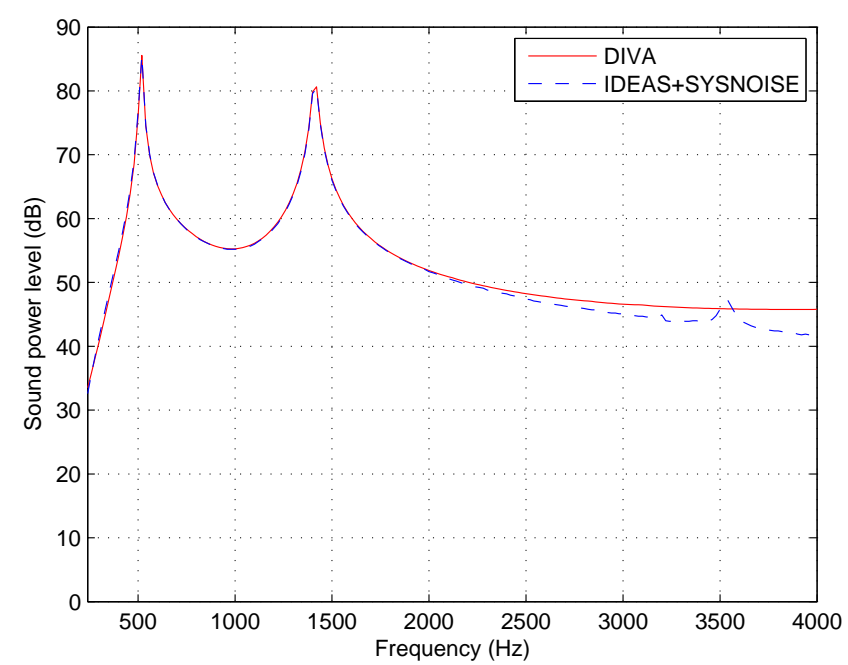

Fig. 9. Sysnoise and DIVA sound power level of a cylindrical shell submitted to two force waves of spatial order 2 and 3 rotating at variable speed. 


$$
\mathbf{C} \frac{d \mathbf{T}}{d t}=\mathbf{G} \mathbf{T}-\mathbf{G}_{b c}\left(\mathbf{T}-T_{a}\right)+\mathbf{P}
$$

where $\mathbf{T}$ is the vector of nodes temperature, $\mathbf{C}$ is the diagonal matrix of capacities, $\mathbf{G}$ is the conductances matrix, $\mathbf{G}_{b c}$ is the conductances matrix corresponding to boundary conditions $\left(T_{a}\right.$ being the ambient temperature outside the motor), and $\mathbf{P}$ is the vector of heat sources. Matlab (C)is used to solve the problem.

Those matrices are constructed automatically from geometrical, dynamical and flow data by an algorithm which recognizes the type of media (air, copper, steel) associated to a node $i$ and its neighbors $j$. Therefore, the code calculates $G_{i j}$ depending if the thermal phenomena between node $i$ and node $j$ is conduction, convection or fluid transport. Building the matrix $G$ therefore needs a good knowledge of the geometry and of the thermal behaviours of the used materials is needed. Moreover, the originality of the present method is to include a temperature calculation in the air inside the machine, taking into account the flow direction and mass flow rate. In order to obtain these data, the volume finite commercial code Fluent (C)is used. It also permits to determine the convective heat transfer coefficients in certain parts of the motor. Firstly, a 3D calculation of the whole motor is done on a simplified geometry, in order to save computational time. However, the number of cells reaches 2300000 due to the weak spacing inside the airgap. That simulation uses the sliding mesh technique to couple stationary and rotary parts, that are displayed in Fig. 10). A standard $k-\varepsilon$ turbulence model is used with the "standard wall function" activated. It gives the main flow inside the motor as shown in Fig. 11.

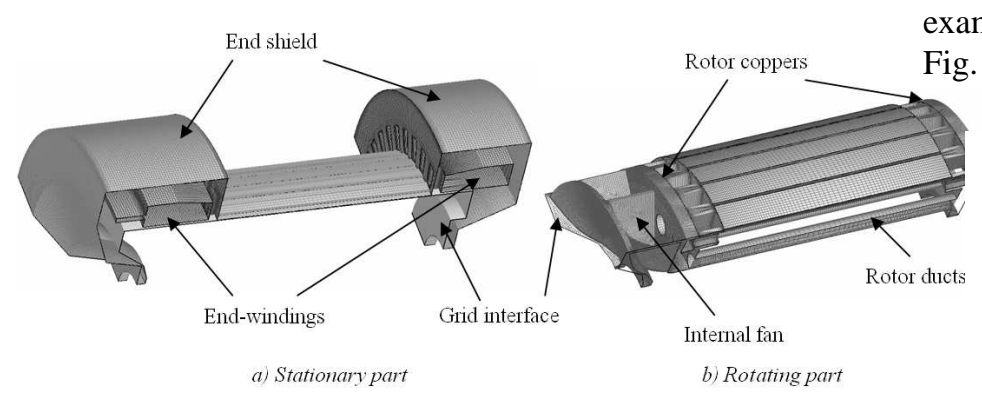

Fig. 10. Geometries of stationary and rotary parts of the motor.

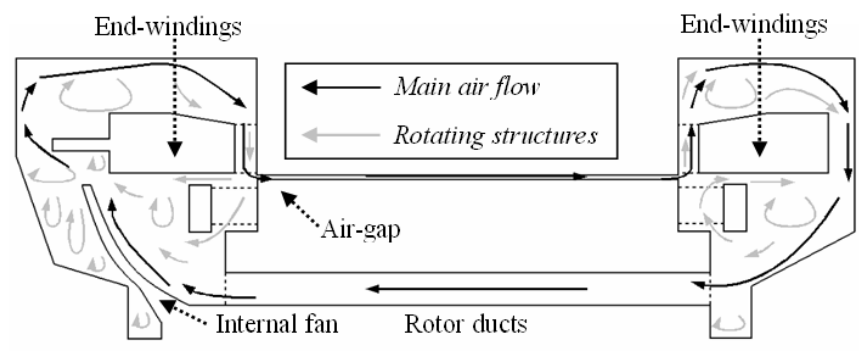

Fig. 11. Representation of the flow structures.

Then, areas where more precision is expected are more precisely simulated with a $3 \mathrm{D}$ model in the cavity which has an internal fan (1950000 cells) and a 2D model for the other cavity (20000 cells). For the both calculation, a $k-\varepsilon$ turbulence model is used with the "enhanced wall treatment" option activated. A thermal resolution is also used in order to estimate the convective heat transfer coefficients in the both cavities. Fig. 12 shows some results obtained from the calculation of the cavity with fan.

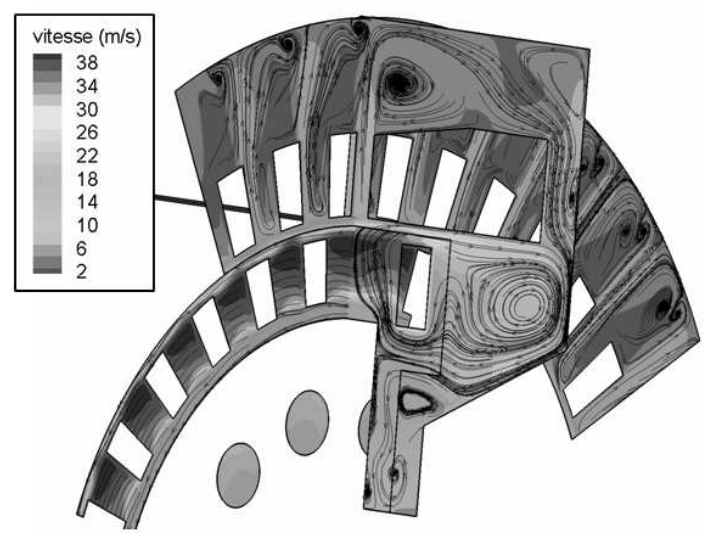

Fig. 12. Velocity field in the cavity.

Convective heat transfer coefficients have therefore been expressed as polynomial functions of speed [16].

The Fluent calculation also helps to highlight the parts that can be represented by an isothermal volume. The topology of the motor, a three-phase squirrel-cage self-ventilated closed induction machine, is represented in Fig. 13 where the 11 different layers of the nodal network have been displayed. An example of the positions and types of nodes is displayed in Fig. 14.

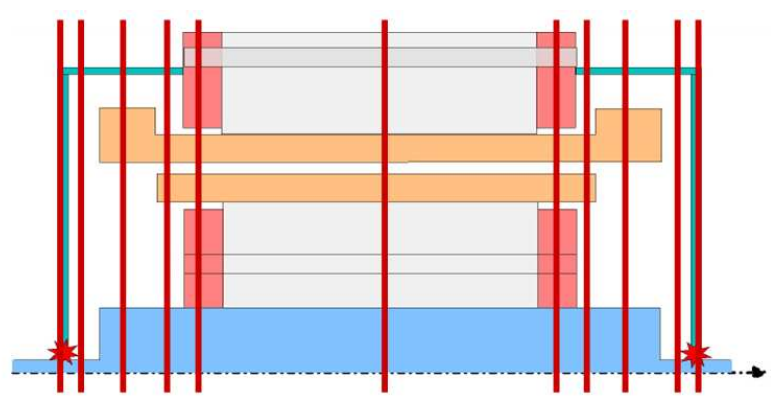

Fig. 13. Representation of the 11 nodal network layers in a half motor.

Heat sources are due to Joule losses, iron losses and friction losses. Joule losses and iron losses are determined on the base of the electromagnetic model. Friction losses account for aerodynamic friction in the air-gap, and mechanical friction due to bearings. A formulation by Harris [17] is used as far as the bearings are concerned, taking into account the axial and radial forces, the type of bearings, the rotational speed and the type of lubrifiant. Aerodynamic losses are estimated as the difference between the total mechanical losses and the calculated bearings losses. They are then associated with solid or air nodes. Repartition is obtained by comparing computed 


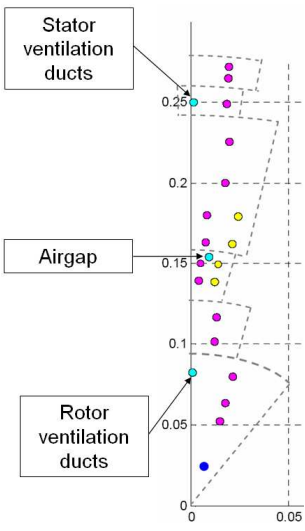

Fig. 14. Representation of the middle layer nodes.

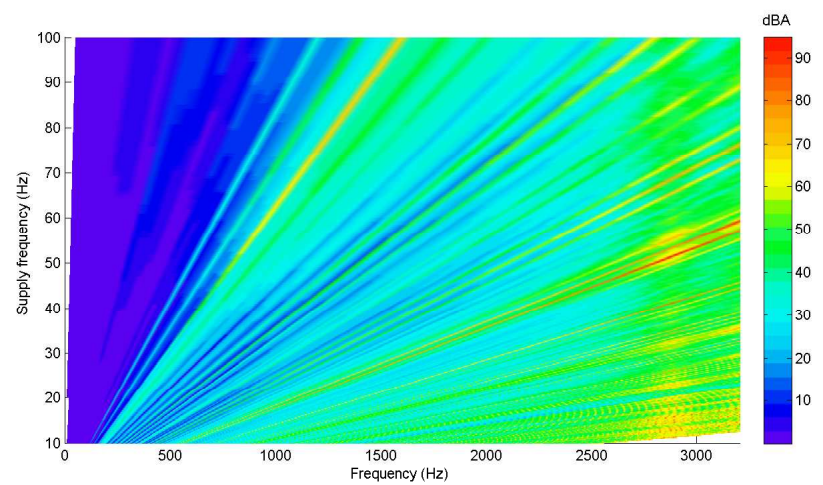

Fig. 15. Simulated sonagram in sinusoidal off-load case.

and experimental temperatures on a test where the motor is towed away by an other motor.

At the end of the thermal calculation, when the steady state is reached, rotor bar temperature and stator winding temperature can be injected in the electromagnetic model, affecting the resistances values, in order to compute the traction characteristics of the motor under thermal constraints.

\section{Simulation RESUlts}

The simulation is run in sinusoidal case at $3000 \mathrm{rpm}$, with a $1.35 \%$ slip and a $250 \mathrm{~V}$ phase voltage. The output power computed by DIVA is $325 \mathrm{~kW}$, the phase current is $535 \mathrm{~A}$. The noise spectrum due to the exciting force distribution presented in Fig. 7 was evaluated at variable speed (sonagram of Fig. 15).

As far as the thermal results are concerned, they can be compared to experimental data obtained by testing the studied motor. About 60 thermocouples were placed inside the whole motor, allowing to measure the air, shaft, copper, end windings and sheet temperatures in different locations with a precision of about $1 \mathrm{~K}$. The thermocouples placed inside the rotating part wee linked to the acquisition center by a rotating mercury ring collector. Also, a CEDIP infrared camera were used in order to measure the external temperatures of the whole engine at a frequency of $25 \mathrm{~Hz}$. The external wall of the machine was covered by a black paint whose emissivity was supposed to be about $0.93 \pm 0.01$. However, it was not possible to calibrate it.

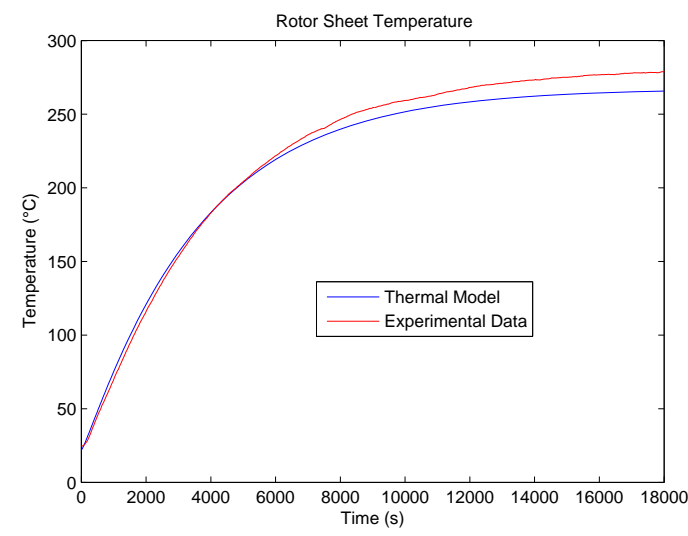

Fig. 16. Rotor Sheet mean temperature.

The camera gives a precision of about $2 \mathrm{~K}$ on the external temperatures. The ambiant temperature was also measured and the test was performed during a transient evolution from ambiant to steady state. Tests were performed in transient state for several configurations: on load for 1500, 2200, 3000 and $3500 \mathrm{rpm}$, with no load for $3000 \mathrm{rpm}$. Those experiments allowed us to use a losses separation method in order to get Joule, iron and friction losses. Iron and friction losses were given by the engine manufacturer. Stator Joule losses are then basically obtained using the temperature and the statoric current with the following formulation:

$$
P_{j}^{S}=3 R_{C u \text { stator }}(T) I_{\text {stator }}^{2}
$$

Rotor Joule losses are computed with the slip $g$ and the power which is transmitted to the rotor:

$$
P_{j}^{R}=g\left(P_{\text {absorbed }}-P_{j}^{S}-\left(P_{i r}^{S T}+P_{i r}^{S Y}\right)\right)
$$

where $P_{i r}^{S T}+P_{i r}^{S Y}$ is evaluated by splitting the total iron losses as $60 \%$ for the stator and $40 \%$ for the rotor (this repartition was validated by FLUX2D calculations, cf. Fig. 4). With this method, for the configuration presented in this paper, losses are given in Table II.

TABLE II

LOSSES AT 3000 RPM

\begin{tabular}{|c|c|}
\hline Type & Experiments \\
\hline Stator Joule Losses & $3317 \mathrm{~W}$ \\
Rotor Joule Losses & $3082 \mathrm{~W}$ \\
Iron Losses & $2588 \mathrm{~W}$ \\
Friction Losses & $2489 \mathrm{~W}$ \\
\hline
\end{tabular}

The evolution of rotor and stator mean temperatures is displayed in figures Fig. 16 and Fig. 17 and compared to experimental data.

Results are in good agreement even if in the both cases, the thermal model slightly underestimates the temperatures when the steady-state is reached. However, the differences does not exceed $20 \mathrm{~K}$. As far as the time evolution is concerned, figures show that the model estimation is consistent with the measured data.

Fig. 18 shows a map of the calculated temperatures in different part of the electrical machine. It can be seen that the rotor is the hottest part and it gives heat to the surrounding 


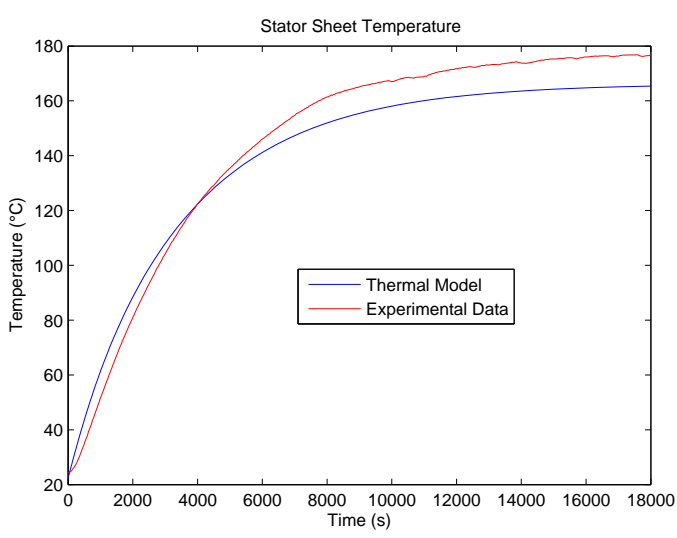

Fig. 17. Stator Sheet mean temperature.

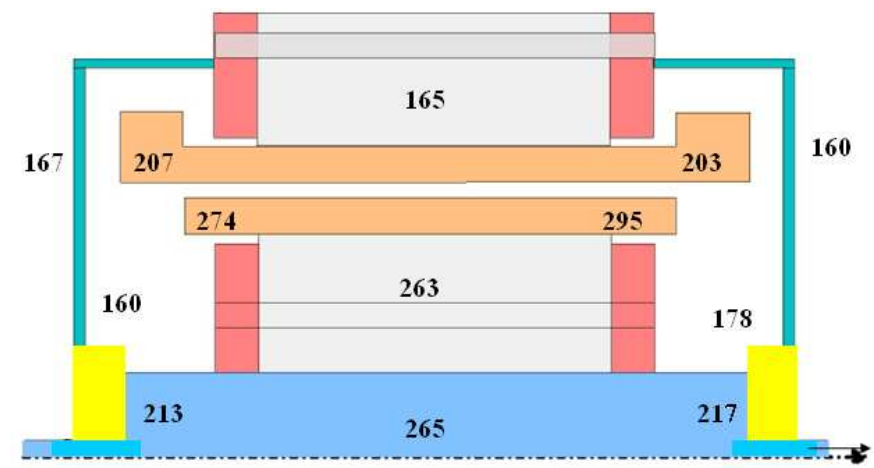

Fig. 18. Computed temperature field.

part: the air and the shaft. Those two media transmit the heat to the other parts of the machine.

As the studied case is a closed machine and the reached temperatures are high, several tests have been performed in order to improve the cooling. It is concluded that only an increase in the external cooling conditions has a positive influence. Internal flow only influences the repartition of the temperature but does not improve the global cooling of the rotor [7].

\section{CONCLUSION}

A multi-physics model of a closed enclosure self-ventilated squirrel-cage induction machine has been built. It includes a nodal network model predicting the temperature field in the machine, an electrical model computing the traction characteristics of the machine, and an acoustic model predicting the audible magnetic noise level radiated by the machine. This fully analytical model was validated at all stages by numerical methods (finite element method, boundary element method, finite volume element method) and/or tests. Its fast computation time allows to carry optimizations using an evolutionary algorithm [18].

While PWM noise is properly handled by the model, the iron losses model does not account for time harmonics yet. Future work therefore aims at modeling harmonic losses, and also inverter losses in order to find the optimal choice of the switching frequency minimizing both the noise level, and the total motor and inverter losses.

\section{ACKNOWLEDGMENTS}

We thank the ADEME, and the region Nord-Pas de Calais (CNRT Operation Futurelec 3) who have partly supported this work.

\section{REFERENCES}

[1] J. L. Besnerais, V. Lanfranchi, M. Hecquet, and P. Brochet, "Multiobjective optimization of the induction machine with minimization of audible electromagnetic noise," European Physics Journal - Applied Physics, vol. 39, no. 2, Aug. 2007.

[2] — , "Multi-objective optimization of induction machines including mixed variables and noise minimization," IEEE Trans. on Mag., vol. 44, no. 6, June 2008.

[3] M. Liwschitz, Calcul des machines électriques. Spes Lausanne, 1967.

[4] I. Boldea and S. A. Nasar, The induction machine handbook. CRC Press, 2002.

[5] A. Hubert, "Contribution l'étude des bruits acoustiques générés lors de l'association machines électriques - convertisseurs statiques de puissances - application à la machine asynchrone," Ph.D. dissertation, Université des Technologies de Compiègne, France, Dec. 2000.

[6] J. L. Besnerais, V. Lanfranchi, M. Hecquet, P. Brochet, and G. Friedrich, "Acoustic noise of electromagnetic origin in a fractional-slot induction machine," COMPEL, vol. 27, no. 5, Feb. 2008.

[7] A. Fasquelle, "Contribution la modélisation multi-physique : électrovibro-acoustique et aérothermique de machines de traction," Ph.D. dissertation, Université des Sciences et Technologies de Lille, France, Nov. 2007.

[8] A. Fasquelle, A. Ansel, S. Brisset, M. Hecquet, P. Brochet, and A. Randria, "Iron losses distribution in a railway traction induction motor," in Proc. of the International Conference on Electrical Machines (ICEM'06), Chania, Greece, July 2006.

[9] J. L. Besnerais, A. Fasquelle, M. Hecquet, V. Lanfranchi, P. Brochet, and A. Randria, "A fast noise-predictive multiphysical model of the PWMcontrolled induction machine," in Proc. of the International Conference on Electrical Machines (ICEM'06), Chania, Greece, July 2006.

[10] P. Alger, Induction machines : their behaviour and uses. Gordon and Breach Science Publishers, 1970.

[11] S. J. Yang, Low noise electrical motors. Oxford: Clarendon Press, 1981.

[12] P. Timar, Noise and vibration of electrical machines. Elsever, 1989.

[13] J. L. Besnerais, V. Lanfranchi, M. Hecquet, P. Brochet, and G. Friedrich, "Characterisation of the radial vibration force and vibration behaviour of a pwm-fed fractional-slot induction machine," IET, accepted for publication.

[14] P. Timar and J. Lai, "Acoustic noise of electromagnetic origin in an ideal frequency-converter-driven induction motor," IEE Proc. on Electr. Power Appl., vol. 141, no. 6, Nov. 1994.

[15] J. L. Besnerais, V. Lanfranchi, M. Hecquet, and P. Brochet, "Bruit audible d'origine magnétique des machines asynchrones," Techniques de l'Ingénieur, vol. D6, no. D 3580, Aug. 2008.

[16] A. Fasquelle, D. Saury, S. Harmand, and A. Randria, "Numerical study of convective heat transfer in end region of enclosed induction motor of railway traction," IJEET International Journal of Electrical Engineering in Transportation, Dec. 2006.

[17] T. Harris, Rolling bearing analysis. New York, USA: Wiley Press, 1966.

[18] J. L. Besnerais, A. Fasquelle, V. Lanfranchi, M. Hecquet, and P. Brochet, "Mixed-variable optimal design of induction motors including efficiency, noise and thermal criteria," in Proc. of the International Conference on Engineering and Optimization, Rio de Janeiro, Brazil, June 2008. 